\title{
T-cell activation and receptor downmodulation precede deletion induced by mucosally administered antigen
}

\author{
Jacqueline M. Benson, ${ }^{1}$ Kim A. Campbell, ${ }^{1}$ Zhen Guan, ${ }^{2}$ Ingrid E. Gienapp, ${ }^{1}$ \\ Scott S. Stuckman, ${ }^{1}$ Thomas Forsthuber, ${ }^{3}$ and Caroline C. Whitacre ${ }^{1}$ \\ ${ }^{1}$ Department of Molecular Virology, Immunology and Medical Genetics, and \\ ${ }^{2}$ Department of Physiology and Cell Biology, The Ohio State University, College of Medicine and Public Health, \\ Columbus, Ohio, USA \\ ${ }^{3}$ Case Western Reserve University, Department of Pathology, Cleveland, Ohio, USA
}

Address correspondence to: Caroline C. Whitacre, The Ohio State University, Department of Molecular Virology, Immunology and Medical Genetics, 2078 Graves Hall, 333 West 10th Avenue, Columbus, Ohio 43210-1239, USA. Phone: (614) 292-5525; Fax: (614) 292-9805; E-mail: whitacre.3@osu.edu.

Jacqueline M. Benson's present address is: Stanford University School of Medicine, Stanford, California, USA.

Received for publication July 11, 2000, and accepted in revised form September 5, 2000.

\begin{abstract}
The fate of antigen-specific $\mathrm{T}$ cells was characterized in myelin basic protein (MBP) T-cell receptor (TCR) transgenic (Tg) mice after oral administration of MBP. Peripheral Th cells are immediately activated in vivo, as indicated by upregulation of CD69 and increased cytokine responses (Th1 and Th2). Concurrently, surface TCR expression diminishes and internal TCR levels increase. When challenged for experimental autoimmune encephalomyelitis during TCR downmodulation, $\mathrm{Tg}$ mice are protected from disease. To characterize Th cells at later times after antigen feeding, it was necessary to prevent thymic release of naive $\mathrm{Tg}$ cells. Therefore, adult $\mathrm{Tg}$ mice were thymectomized before treatment. TCR expression returns in thymectomized Tg mice 3 days after MBP feeding and then ultimately declines in conjunction with MBP-specific proliferation and cytokine responses (Th1-type and Th2-type). The decline correlates with an increase in apoptosis. Collectively, these results demonstrate that a high dose of fed antigen induces early T-cell activation and TCR downmodulation, followed by an intermediate stage of anergy and subsequent deletion.
\end{abstract}

J. Clin. Invest. 106:1031-1038 (2000).

\section{Introduction}

Clinical, histopathological, and immunological similarities between experimental autoimmune encephalomyelitis (EAE) and the human central nervous system (CNS) autoimmune disorder multiple sclerosis (MS) allow EAE to be used to test immunotherapeutic strategies for MS. We and others have demonstrated amelioration of EAE via alteration in autoantigen-specific T-cell function after oral administration of a CNS protein (myelin basic protein, or MBP) (1-4). The mechanism by which the pathogenic $\mathrm{T}$ cells are rendered tolerant to self-antigen is determined by the dose of fed antigen. Repeated low doses (microgram to $1 \mathrm{mg}$ range) are reported to induce TGF- $\beta$ release from antigen-specific suppressor $T$ cells $(5,6)$, or immune deviation from a "pro-inflammatory" Th1 to a "suppressive" Th2 cytokine profile (7). Alternatively, high doses of orally administered antigen (> $1 \mathrm{mg}$ ) may promote trafficking of antigen-specific $T$ cells from the periphery to the gut (8), or anergy (9-11) and/or deletion of antigen-specific $\mathrm{T}$ cells $(12,13)$.

Deciphering the mechanisms of oral tolerance in conventional mice is hindered by the low frequency of antigen-specific cells. Therefore, we utilized MBP T-cell receptor (TCR) transgenic ( $\mathrm{Tg}$ ) mice, in which $95 \%$ of
$\mathrm{CD}^{+} \mathrm{T}$ cells express a V $44 / \mathrm{V} \beta 8.2 \mathrm{TCR}$ specific for the immunodominant NAc1-11 encephalitogenic epitope of MBP (14). Using these mice, we characterized MBPspecific $\mathrm{Tg} \mathrm{T}$ cells over time after a high dose of orally administered MBP. The influence of new Tg thymic emigrants was eliminated by thymectomizing adult MBP TCR Tg mice before feeding. We found that a single high dose of MBP induces immediate TCR downmodulation and T-cell activation in vivo, which corresponds with protection from EAE. Subsequently, $T$ cells enter an anergic state, followed by an eventual decline in T-cell number and function with evidence of apoptosis.

\section{Methods}

Animals. B10.PL V $\alpha 4 / V \beta 8.2$ MBP TCR Tg mice were obtained from C. Janeway (Yale University, New Haven, Connecticut, USA) and maintained in the Tg animal facility at The Ohio State University (OSU). Progeny were screened by flow cytometry for expression of the $\mathrm{V} \beta 8.2$ transgene on $\mathrm{CD}^{+}$blood lymphocytes. $\mathrm{Tg}^{+}$mice were used in experiments at 6-8 weeks of age.

Neuroantigens. MBP was extracted from guinea pig spinal cords (Harlan Sprague-Dawley, Indianapolis, Indiana, USA) using the method of Deibler et al. (15) or Swanborg et al. (16). NAc1-11 MBP peptide (ASQKRPSQRHG) was synthesized by the OSU peptide facility. 
Induction of oral tolerance. Mice were deprived of food, but not water, for 4-6 hours before oral antigen administration. MBP (in $0.5 \mathrm{ml}$ PBS) was administered by gastric intubation to anesthetized mice. Control Tg mice were either untreated or were fed vehicle (PBS) or 100 mg ovalbumin (OVA). There were no observable differences between control groups.

Flow cytometry. A total of $0.5 \times 10^{6}$ cells were stained with: FITC anti-V $\beta$ 8.1/8.2; FITC anti-I-A ${ }^{\text {b; }}$ cychrome anti-CD4; FITC anti-CD62L; FITC anti-CD44; FITC anti-CD69; phycoerythrin (PE) anti-CD45RB; PE antiFasL; and PE anti-Fas (PharMingen, San Diego, California, USA). Isotype controls: mouse $\operatorname{IgG}_{2 \mathrm{a}}$ and $\operatorname{IgG}_{2 \mathrm{~b}}$, rat $I g G_{2 a}$ and $\operatorname{IgG}_{2 b}$, and hamster $\operatorname{IgG}$ were run with each sample and matched for fluorochrome. After a 30-minute incubation, cells were washed and resuspended in $1 \%$ paraformaldehyde. Analysis was performed on an Epics XL flow cytometer (Beckman Coulter Inc., Miami, Florida, USA). Forward and right angle light scatter was used to gate the lymphocyte population and exclude monocytes/macrophages, granulocytes, and dead cells.

Analysis of intracellular TCR expression was performed using the Immunotech IntraPrep Permeabilization Reagent kit (Coulter Electronics Ltd.) with modifications. Briefly, $10^{6}$ cells were incubated with FITC anti-V $\beta$ 8.1/8.2 in 30\% mouse serum (Sigma Chemical Co., St. Louis Missouri, USA). After washing, cells were incubated with a three- to fivefold excess of purified anti-V $\beta$ 8.1/8.2 to saturate extracellular TCR sites. Cells were then washed, fixed, and permeabilized according to manufacturer's instructions. Cells were incubated with $\mathrm{PE}$ anti-V $\beta$ 8.1/8.2 for intracellular $\mathrm{V} \beta$ protein detection and then washed, resuspended in $0.5 \%$ paraformaldehyde, and analyzed (at least 10,000 events) by flow cytometry.

Induction of EAE. Tg mice were injected subcutaneously over four sites on the back with $100 \mu \mathrm{l}$ containing $200 \mu \mathrm{g}$ MBP combined with CFA (containing $200 \mu \mathrm{g}$ heat-killed Mycobacterium tuberculosis Jamaica strain). Mice also received $200 \mathrm{ng}$ pertussis toxin (List Biological, Campbell, California, USA) intraperitoneally in $0.2 \mathrm{ml} \mathrm{PBS}$, at the time of immunization and 48 hours later. For passive EAE, lymph node (LN) and spleen (SPL) cells were cultured in vitro with MBP and transferred intraperitoneally $\left(10 \times 10^{6}\right)$ to B10.PL recipients. Mice were also given pertussis toxin as already described here. All animals were observed daily for clinical signs and scored as follows: limp tail or waddling gait with tail tonicity, 1 ; waddling gait with limp tail (ataxia), 2; ataxia with partial limb paralysis, 2.5; full paralysis of one limb, 3; full paralysis of one limb with partial paralysis of second limb, 3.5; full paralysis of two limbs, 4; moribund, 4.5; and death, 5.

Adult thymectomy. Thymectomy surgery was performed under a dissecting microscope as reported elsewhere (17). Adult Tg mice were given $20 \mu \mathrm{g}$ gentocin intraperitoneally and were then anesthetized with ketamine $(82-110 \mathrm{mg} / \mathrm{kg})$ and xylazine $(7.5 \mathrm{mg} / \mathrm{kg})$ intraperitoneally. During surgery, mice were intubated and maintained on a rodent ventilator. An upper median sternotomy was performed, and both lobes of the thymus were dissected and removed. The thoracic cage was sutured closed and the skin was secured; mice were then extubated and provided with oxygen. Regular breathing resumed within 1 minute of extubation, and the entire procedure lasted approximately 10-15 minutes per animal. Sham surgery control mice were anesthetized and intubated; the thoracic cage was then opened and sutured closed. Mice were used in experiments 7-10 days after surgery.

Cytokine ELISPOT. ELISPOT analysis was performed as described elsewhere (18). Plates (Whatman Polyfiltronics, Rockland, Massachusetts, USA) were coated overnight with: $2 \mu \mathrm{g} / \mathrm{ml}$ anti-IL-2, $4 \mu \mathrm{g} / \mathrm{ml}$ anti-IL-4, 5 $\mu \mathrm{g} / \mathrm{ml}$ anti-IL-5, and $4 \mu \mathrm{g} / \mathrm{ml}$ anti-IFN- $\gamma$ (PharMingen). Plates were blocked for 1 hour, and then LN cells $\left(5 \times 10^{5}\right.$ per $\left.0.1 \mathrm{ml}\right)$ were resuspended in HL- 1 medium (BioWhittaker Inc., Walkersville, Maryland, USA) with $1 \% \mathrm{~L}$-glutamine and 1:1,000 gentamicin and added to replicate wells with $40 \mu \mathrm{g} / \mathrm{ml} \mathrm{MBP}, 40 \mu \mathrm{g} / \mathrm{ml}$ OVA (Sigma Chemical Co.), $1-5 \mu \mathrm{g} / \mathrm{ml}$ anti-CD3ع (PharMingen), or medium alone. Cultures were incubated for 24 (IL-2, IFN- $\gamma$ ) or 48 (IL-4, IL-5) hours and were then washed and secondary antibodies added: $2 \mu \mathrm{g} / \mathrm{ml}$ biotinylated anti-IL-2, anti-IL-4, and anti-IFN- $\gamma$, and $4 \mu \mathrm{g} / \mathrm{ml}$ biotinylated anti-IL-5 (PharMingen). After overnight incubation, plates were washed and incubated with alkaline phosphatase conjugated goat antibiotin IgG (Vector Laboratories, Burlingame, California, USA) for 2 hours. Plates were washed, developed with BCIP/NBT phosphatase substrate (Kirkegaard \& Perry Laboratories, Gaithersburg, Maryland, USA), and dried and analyzed by computer-assisted image analysis using a Series I Immunospot Image Analyzer (Cellular Technology, Cleveland, Ohio, USA).

TGF- $\beta$ ELISA. TGF- $\beta$ analysis was performed as described elsewhere (19). Supernatants were harvested from SPL cells $\left(4 \times 10^{6} / \mathrm{ml}\right)$ cultured in X-Vivo serumfree medium (BioWhittaker) for 72 hours \pm MBP (40 $\mu \mathrm{g} / \mathrm{ml})$. Chicken anti-TGF- $\beta(2.5 \mu \mathrm{g} / \mathrm{ml})$ (R\&D Systems Inc., Minneapolis, Minnesota, USA) was incubated in Immulon II plates (Dynatech Laboratories, Chantilly, Virginia, USA) at $4^{\circ} \mathrm{C}$ overnight. Plates were blocked with $0.25 \%$ gelatin (Bio-Rad Laboratories Inc., Hercules, California, USA) for 1 hour, and then sample $(100 \mu \mathrm{l})$ or standard dilutions of hu rTGF $\beta$ (R\&D Systems Inc.) were added for 2 hours. Mouse anti-TGF- $\beta$ $1,2,3(1 \mu \mathrm{g} / \mathrm{ml})$ (Genzyme Pharmaceuticals, Cambridge, Massachusetts, USA) was added for 45 minutes, followed by $1 \mu \mathrm{g} / \mathrm{ml}$ of biotinylated horse anti-mouse IgG (Vector Laboratories). Avidin-peroxidase (Sigma Chemical Co.) was added and incubated, and then plates were developed with 2,2'azino-di-3ethyl-benzthiazoline sulfonate di-ammonium salt (ABTS) substrate (Boehringer Mannheim, Indianapolis, Indiana, USA). Samples were read at $405 \mathrm{~nm}$ on a Bio-Rad ELISA reader (Bio-Rad Laboratories Inc.). 
Lymphocyte proliferation. SPL, LN, or mesenteric lymph node (MLN) cells were cultured in RPMI 1640 containing 10\% FBS, $25 \mathrm{mM}$ HEPES, $2 \mathrm{mM}$ L-glutamine, $50 \mathrm{U} / \mathrm{ml}$ penicillin, $50 \mu \mathrm{g} / \mathrm{ml}$ streptomycin, and $5 \times$ $10^{-5} \mathrm{M} 2$-mercaptoethanol in round-bottom 96-well plates $\left(5 \times 10^{5}\right.$ cells per well). Cells were cultured with NAc1-11 $(10 \mu \mathrm{g} / \mathrm{ml})$ or medium alone in triplicate for 72 hours, including a final 18-hour pulse with $\left[{ }^{3} \mathrm{H}\right]$ thymidine. Cultures were harvested onto glass fiber filter mats using a Skatron harvester (Molecular Devices Corp., Sunnyvale, California, USA) and counted by liquid scintillation on a Wallac Betaplate (Wallac Inc., Gaithersburg, Maryland, USA).

Apoptosis analysis. Analysis of DNA fragmentation was performed by TdT-mediated dUTP nick end labeling (TUNEL) (Boehringer Mannheim). Cells $\left(10^{6}\right)$ were stained with PE-anti-V $\beta 8$ and Cyc-anti-CD4, fixed with $4 \%$ paraformaldehyde, permeabilized with $0.1 \%$ TritonX-100/0.1\% sodium citrate, and exposed to the $\mathrm{TdT} /$ biotin-dUTP mix for 1 hour at $37^{\circ} \mathrm{C}$. FITC-streptavidin was added for 30 minutes, followed by washing. Positive control samples were treated with DNase (Genzyme Pharmaceuticals) for 10 minutes before TdT labeling, whereas negative control samples contained no TdT. Annexin V staining was performed according to the manufacturer's instructions (Boehringer Mannheim). TUNEL and Annexin V stained samples (at least 10,000 events) were analyzed on an Epics XL flow cytometer.

Statistical analysis. A nonparametric ANOVA with Kruskal-Wallis analysis was utilized to determine differences between groups. All values were considered significantly different at $P \leq 0.05$.

\section{Results}

A single bigh dose of orally administered antigen induces immediate TCR downmodulation. Considering the high frequency of MBP-specific T cells in MBP TCR Tg mice, it was first necessary to establish the appropriate dose for oral administration of MBP. Tg mice were fed either low doses ( $1 \mathrm{mg}$ ) of MBP every other day for 10 days (five feeds) or increasing single doses $(5,25,50$, or $100 \mathrm{mg}$ ) of MBP. One day after feeding, peripheral lymphocytes were analyzed by flow cytometry for $\mathrm{Tg}$ V $\beta 8$ TCR expression on $\mathrm{CD}^{+}$cells. Repeated low oral doses of MBP decreased the percentage of $\mathrm{V} \beta 8^{+} / \mathrm{CD}^{+}$ cells in peripheral LNs (axillary, brachial, cervical, deep cervical, inguinal, mandibular, popliteal, periaortic) (Figure 1a). However, profound decreases were observed in the blood and LN after a single oral administration of 25, 50, or $100 \mathrm{mg}$ of MBP. Similar reductions were observed in SPL and MLN cell preparations, but only following a single $100-\mathrm{mg}$ dose of MBP (data not shown). These data suggest that a single high oral dose of MBP has the most significant effect on the MBP-specific population.

To determine if the early reduction of $\mathrm{V} \beta 8^{+} / \mathrm{CD}^{+} \mathrm{Tg}$ cells was maintained, the MBP-specific T-cell population was assessed 1 or 3 days after MBP feeding (100 $\mathrm{mg})$. Oral administration of an irrelevant antigen (OVA) had no effect on $\mathrm{V} \beta 8^{+} / \mathrm{CD}^{+} \mathrm{T}$-cell populations (Figure 1b). However, there was a significant reduction

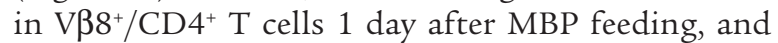
there was a return of the $\mathrm{Tg}$ population by day 3 . Similar observations were made in SPL and MLN (data not shown). It has been proposed that orally administered antigen can induce trafficking of antigen-specific $\mathrm{T}$ cells out of organized lymphoid compartments (8). However, despite a significant reduction in the per-
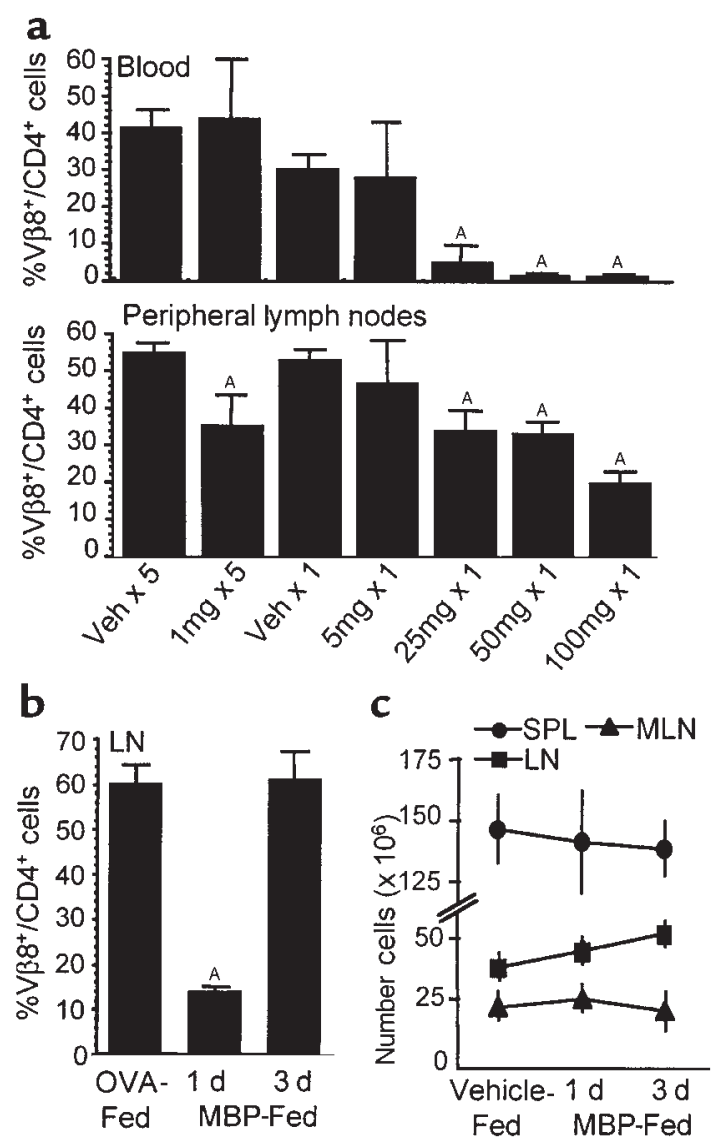

Figure 1

A single high dose of orally administered antigen reduces TCR expression without affecting lymphoid organ cellularity. (a) MBP TCR Tg mice were fed vehicle or $1 \mathrm{mg}$ MBP every other day for 10 days (five feeds), or vehicle or 5, 25, 50, or $100 \mathrm{mg} \mathrm{MBP}$ once. Lymphocytes were analyzed by flow cytometry 1 day after the last feeding for expression of the $\mathrm{Tg} V \beta 8.2 \mathrm{TCR}$ on $\mathrm{CD} 4^{+}$cells. Each bar is the mean percentage of $\mathrm{V} \beta 8^{+} / \mathrm{CD} 4^{+}$cells $\pm \mathrm{SEM}(n=3)$. ${ }^{\mathrm{A} V a l u e s}$ are statistically different from the corresponding vehicle-fed controls at $P \leq 0.05$. (b) Peripheral LN cells from MBP TCR Tg mice fed $100 \mathrm{mg}$ MBP or 100 mg OVA were analyzed by flow cytometry 1 or 3 days after feeding. Each bar is the mean percentage of $\mathrm{V} \beta 8^{+} / \mathrm{CD} 4^{+}$cells within the lymphocyte population $\pm \operatorname{SEM}(n=3)$. ${ }^{A}$ Values are statistically different from OVA-fed control mice at $P \leq 0.05$. (c) The total number of cells in single-cell suspensions from spleen (SPL), peripheral lymph nodes (LN), and mesenteric LN (MLN) of MBP- or vehicle-fed Tg mice was determined by trypan blue exclusion 1 or 3 days after feeding. Data are reported as the mean number of cells $\times 10^{6} \pm \operatorname{SEM}(n=3-11)$. Values were not statistically different from vehicle-fed control mice. 

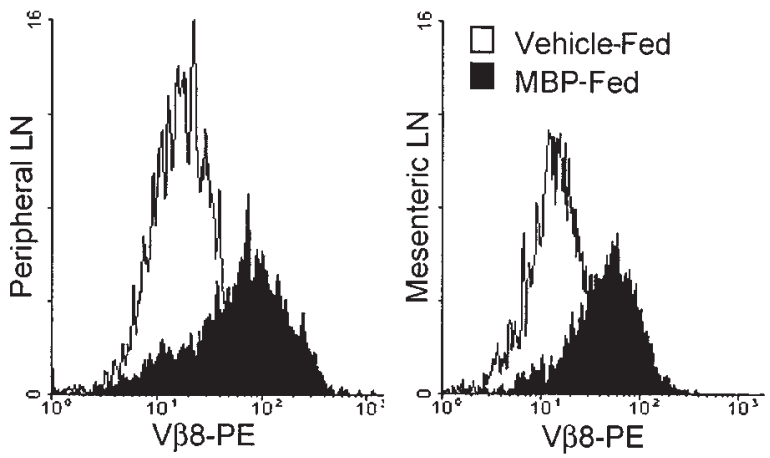

Figure 2

Surface TCR downmodulation corresponds with TCR internalization. Peripheral and mesenteric $L N$ cells from MBP or vehicle-fed Tg mice were analyzed by flow cytometry for surface (FITC) and internal (PE) $\mathrm{Tg}$ V $\beta 8.2 \mathrm{TCR}$ expression 1 day after feeding. Surface $\mathrm{TCR}^{+}$cells were gated and then analyzed for internal TCR staining. Histograms are representative of two separate experiments.

centage of $\mathrm{Tg}$ cells, the total cell numbers collected from SPL, LNs, and MLNs 1 and 3 days after MBP feeding were equivalent to vehicle-fed control mice (Figure 1c). Furthermore, immunohistochemical analysis did not demonstrate an increase of $\mathrm{CD} 4^{+} \mathrm{Tg}$ cells in the lamina propria, Peyer's patches, or liver after MBP feeding (data not shown). These observations suggest that the immediate reduction of $\mathrm{TCR}^{+} \mathrm{Tg}$ cells and their subsequent return is not due to T-cell trafficking.

It is possible that MBP-specific T cells undergo apoptosis within the first 24 hours of a high oral dose of MBP. However, TUNEL and Annexin V staining of lymphocyte populations isolated 1 day after MBP feeding did not demonstrate evidence for apoptosis of $\mathrm{V} \beta 8^{+} / \mathrm{CD}^{+}$cells (data not shown). Furthermore, when the influence of newly derived $\mathrm{V} \beta 8^{+} / \mathrm{CD}^{+}$cells was eliminated by thymectomizing adult MBP TCR Tg mice before feeding, $\mathrm{V} \beta 8^{+} / \mathrm{CD}^{+}$expression was reduced by $78-94 \%$ in SPL, LNs, and MLNs 1 day after feeding, then completely restored by day 3 . Given that the mice were thymectomized and unable to regenerate their T-cell repertoire, the $\mathrm{V} \beta 8^{+} / \mathrm{CD}^{+}$cells present on day 3 must represent the original MBP-specific population. Collectively, these observations suggest that the reduction in $\mathrm{V} \beta 8^{+} / \mathrm{CD}^{+}$cells observed 1 day after antigen feeding is not due to clonal deletion.

Another explanation for reduced $\mathrm{V} \beta 8^{+} / \mathrm{CD}^{+}$expression is antigen-induced TCR downmodulation. To examine this possibility, surface versus internal TCR expression was analyzed. LN and MLN cells were surface-labeled with FITC anti-V $\beta 8.2$ TCR antibody and then permeabilized, and internal TCR was labeled with $P E$ anti-V $\beta 8$ 8. Surface FITC-V $\beta 8.2^{+}$cells were analyzed for internal TCR expression, and Figure 2 demonstrates that MBP feeding increases levels of internal $\mathrm{Tg}$ TCR. The profound reduction in surface $\mathrm{TCR}^{+}$cells 1 day after MBP feeding is also represented in Figure 2 by the reduced number of analyzed cells in the MBP-fed population. Although it cannot be determined whether the internal TCR is newly synthesized protein, these experiments suggest that TCR is internalized in vivo in response to oral administration of a high dose of MBP.

MBP TCR Tg mice are protected from EAE when challenged while TCR expression is reduced. To assess the in vivo effects of oral antigen on Th cell function, $\mathrm{Tg}$ mice were challenged for EAE after MBP feeding. Figure 3 shows that $\mathrm{Tg}$ mice are protected from EAE when challenged during reduced TCR expression (day 1 ), as shown by a reduction in cumulative clinical score (cs), cs per day, and mean highest cs. However, MBP TCR Tg mice challenged when TCR expression is restored (day 3 ) are not protected from disease. When Tg cells are isolated 1 day after vehicle or MBP feeding and stimulated in vitro with MBP, only Tg cells from vehicle-fed mice passively transfer EAE to non-Tg recipients (EAE incidence: $2 / 4$ ). EAE is not induced when cells from MBP-fed mice are transferred (EAE incidence: 0/7). Interestingly, adult Tg mice that were thymectomized, then challenged for EAE 1 day after MBP feeding, demonstrated a 14 day cumulative cs comparable to euthymic mice, but were not completely protected from disease (EAE mortality: $2 / 7$ ) when compared with vehicle-fed thymectomized controls (EAE mortality: 3/4). Thus, onset of disease 13 days after immunization (Figure 3) most likely represents restored function of the Tg cells that would otherwise be rendered tolerant after high-dose MBP feeding.

T-cell activation and cytokine responses are increased early, but later decline after MBP feeding. Ligation of TCR by antigen in vitro can result in TCR downmodulation as the first step in activation (20). Therefore, the activa-

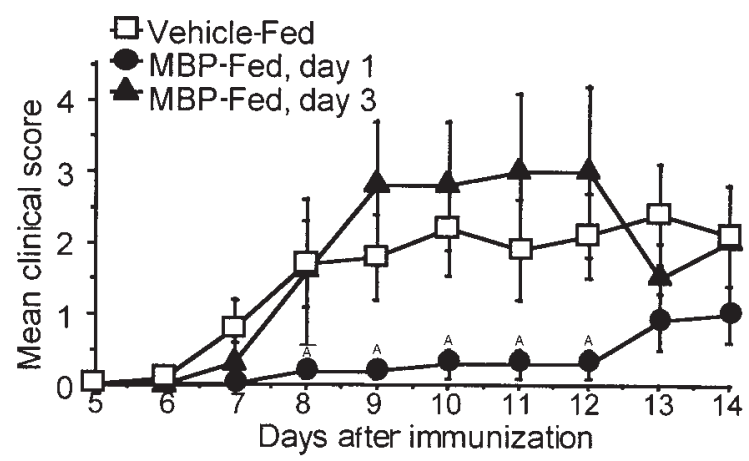

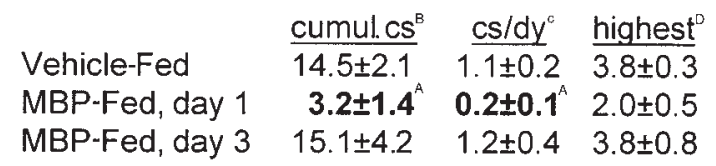

Figure 3

MBP TCR Tg mice are protected from EAE when challenged while TCR expression is reduced. MBP TCR Tg mice were fed vehicle or 100 mg MBP, and EAE was induced 1 or 3 days later by immunization with $\mathrm{MBP} / \mathrm{CFA} /$ pertussis toxin. Mice were scored daily for disease, and the mean score of each group \pm SEM is shown $(n=4-17)$. Clinical scores (cs) from vehicle-fed control mice were pooled regardless of the day of feeding. AValues are statistically different from vehiclefed mice at $P \leq 0.05$. ${ }^{B}$ The group mean of the sum of daily cs through day $14 \pm$ SEM. ${ }^{C}$ The group mean of the cumulative cs divided by the number of days the animal was observed \pm SEM. DThe group mean of the highest cs exhibited by mice with $\mathrm{EAE} \pm \mathrm{SEM}$. 
tion state of $\mathrm{Tg} \mathrm{V} \beta 8^{+} / \mathrm{CD}^{+} \mathrm{T}$ cells was examined by assessing the expression of early activation antigen (CD69), L-selectin (CD62L), CD45RB, and Pgp1 (CD44). Neither CD45RB nor CD44 expression was influenced by MBP feeding (data not shown), suggesting that $\mathrm{Tg} \mathrm{T}$ cells were not triggered to differentiate from naive to memory cells (21). CD62L expression decreased on Tg cells from MLN 1 day after oral MBP and then returned to control levels by day 3 (data not shown). Simultaneously, CD69 expression was profoundly increased on $\mathrm{V} \beta 8^{+} / \mathrm{CD}^{+}$cells 1 day after $\mathrm{MBP}$ feeding in peripheral LNs (Figure 4a), MLNs, SPL, and Peyer's patches and could be detected within 6 hours of MBP feeding. An increase in CD69 and a decrease in CD62L are characteristic of T-cell activation (22). Therefore, concomitant with TCR downmodulation, MBP-specific T cells exhibit an activated phenotype.

To characterize further the functional capacity of the MBP-specific T-cell population, in vitro cytokine responses to MBP were assessed in lymphocytes from adult $\mathrm{Tg}$ mice that were thymectomized before MBP or vehicle feeding. Figure $4 \mathrm{~b}$ shows that TGF- $\beta$ levels are unchanged over time after MBP feeding. In contrast, there are profound increases in Th1 (IL-2, IFN- $\gamma$ ) and Th2 (IL-5, IL-4) MBP-specific cells 1 day after feeding (Figure 4, $\mathrm{c}$ and d). Interestingly, cytokine levels gradually declined to values lower than vehicle-fed control mice by 14 days after oral MBP.

Oral administration of $\mathrm{MBP}$ decreases $\mathrm{V} \beta 8^{+} / \mathrm{CD}^{+}$cell numbers and function. To monitor only those antigen-specific $\mathrm{T}$ cells exposed to a high dose of oral antigen, we compared $\mathrm{VB8^{+ }} / \mathrm{CD} 4^{+}$cells from untreated and thymectomized $\mathrm{Tg}$ mice. Figure 5 shows that $\mathrm{V} \beta 8^{+} / \mathrm{CD}^{+} \mathrm{Tg}$ cells in peripheral blood gradually returned in euthymic Tg mice, whereas $\mathrm{V} \beta 8^{+} / \mathrm{CD} 4^{+}$cells did not return in thymectomized Tg mice fed MBP. In

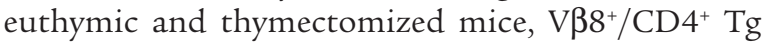
cells in peripheral LNs were profoundly reduced 1 day after MBP feeding and returned 2 days later (day 3 ). However, although $\mathrm{VB8^{+ }} / \mathrm{CD}^{+} \mathrm{Tg}$ cells persist in euthymic Tg mice, thymectomized Tg mice fed MBP exhibit a gradual decline in Tg cells after day 3 (Figure $5 b)$. Similar declines were observed in SPL and MLNs

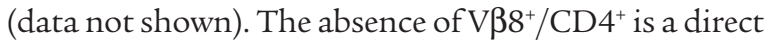
effect of oral administration of MBP because thymectomized mice fed vehicle maintained their $\mathrm{V} \beta 8^{+} / \mathrm{CD}^{+}$ population in all organs examined (data not shown). Furthermore, sham-surgery control mice fed MBP showed similar $\mathrm{V} \beta 8^{+} / \mathrm{CD}^{+}$expression as euthymic MBP-fed mice (data not shown). These data demonstrate that in the absence of the release of naive Tg cells, the peripheral MBP-specific population diminishes 7-14 days after exposure to a high oral dose of MBP. MBP-specific T-cell functional capacity was also assessed by measuring in vitro proliferation responses to MBP NAc1-11. The most robust proliferation occurred with cells isolated 1 day after MBP feeding. LN cells from euthymic $\mathrm{Tg}$ mice demonstrated decreased proliferation to NAc1-11 on days 3 and 7 after feeding (Figure 6a), despite the presence of control levels of $\mathrm{V} \beta 8^{+} / \mathrm{CD}^{+} \mathrm{Tg}$ cells (Figure $5 \mathrm{~b}$ ). Together with the reduction in IL-2 production after feeding (Figure 4c), these observations are indicative of an anergic T-cell population (23). However, by days 10 and 14 , proliferation returned to control levels. The

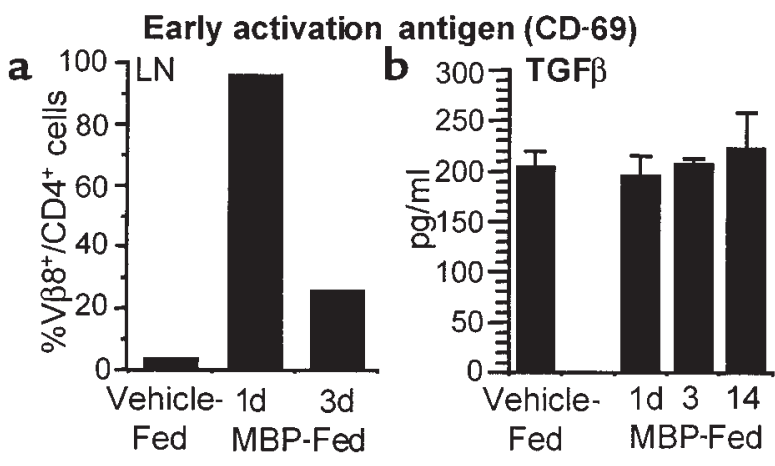

C
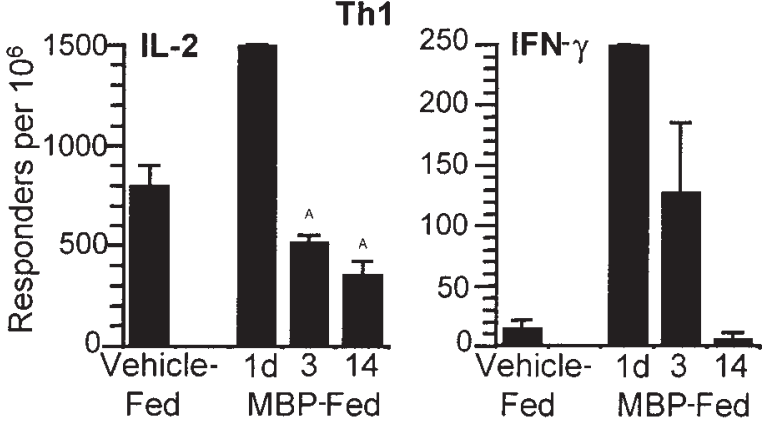

d
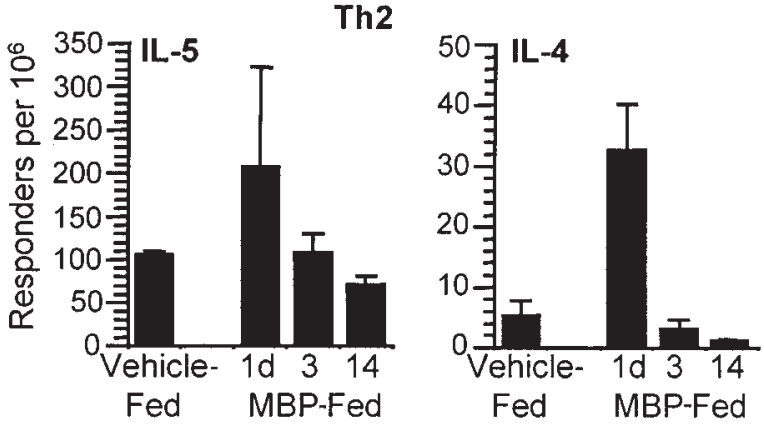

Figure 4

T-cell activation occurs early, and later it declines after MBP feeding. (a) MBP TCR Tg mice were fed vehicle or $100 \mathrm{mg} \mathrm{MBP}$ and sacrificed 1 or 3 days after feeding. Peripheral LNs were harvested from three animals per group, and pooled single-cell suspensions were analyzed by flow cytometry for early activation antigen (CD69) expression within $\mathrm{V} \beta 8^{+} / \mathrm{CD}^{+} \mathrm{Tg}$ populations. (b-d) Adult MBP TCR Tg mice were thymectomized, then fed vehicle or $100 \mathrm{mg}$ MBP, and sacrificed on days 1,3 , and 14 after feeding. TGF- $\beta$ production was measured by ELISA from supernatants of splenocytes cultured with MBP. TGF- $\beta$ concentration $(\mathrm{pg} / \mathrm{ml})$ was determined from a standard curve for duplicate cultures from individual animals, and the mean for each group \pm SEM is shown $(n=2-4)$. Values were not statistically different from vehicle-fed control mice. IL-2, IFN- $\gamma$, IL-5, and IL-4 production was measured by ELISPOT from LN cells cultured with MBP. There was negligible production of any cytokine without in vitro restimulation with MBP. Responding cells per million were determined for replicate wells from individual animals, and the mean for each group \pm SEM is shown $(n=$ 2-6). ${ }^{A}$ Values are statistically different from vehicle-fed mice at $P \leq 0.05$. 

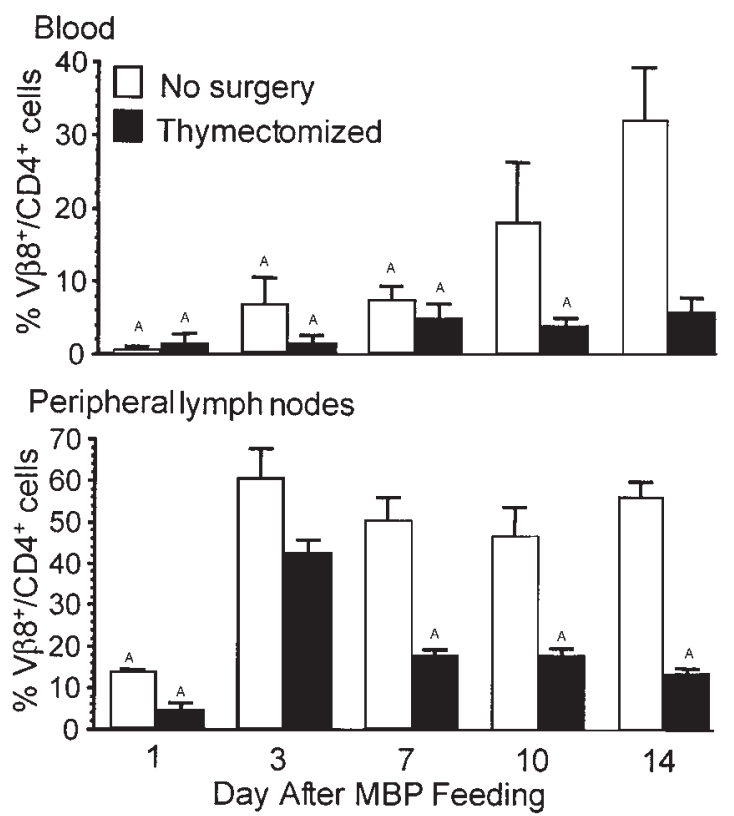

Figure 5

The number of $\mathrm{V} B 8^{+} / \mathrm{CD} 4^{+} \mathrm{Tg} T$ cells declines after MBP feeding. Euthymic and thymectomized MBPTCR Tg mice were fed $100 \mathrm{mg}$ MBP and sacrificed 1, 3, 7, 10, and 14 days after feeding. Cells were analyzed by flow cytometry for the $\mathrm{Tg} V \beta 8 \mathrm{TCR}$ on $\mathrm{CD} 4^{+}$cells. Each bar is the mean percentage of $\mathrm{V} \beta 8^{+} / \mathrm{CD} 4^{+}$cells $\pm \operatorname{SEM}(n=3-5)$. ${ }^{A} V$ alues are statistically different from corresponding control-fed mice at $P \leq 0.05$.

recovery of the proliferation responses most likely represents new thymic emigrants, as proliferation responses were not restored in thymectomized $\mathrm{Tg}$ mice (Figure 6b). There was also evidence for anergy in thymectomized mice 3 days after feeding, when $\mathrm{V} \beta 8^{+} / \mathrm{CD}^{+} \mathrm{Tg}$ cells are present (Figure $5 \mathrm{~b}$ ) but proliferation is reduced (Figure 6b). However, in contrast to early time points after MBP feeding (day 1), later analysis in MBP-fed thymectomized Tg mice shows that functional responses to MBP (cytokine production, proliferation) ultimately decline.

Evidence for apoptosis of MBP-specific T cells after MBP feeding. We assessed the possibility that MBP-specific $\mathrm{T}$ cells were undergoing apoptosis at later time points after exposure to a high oral dose of MBP. Adult MBP TCR Tg mice were thymectomized, fed vehicle or 100 mg MBP, and sacrificed 7 or 10 days later; MLNs were analyzed by flow cytometry for apoptosis. Thymectomized $\mathrm{Tg}$ mice fed MBP exhibited a dramatic increase

Table 1

Evidence for apoptosis of MBP-specific T cells after MBP feeding

Treatment

$\begin{array}{lcc}\text { Analysis } & \begin{array}{c}\text { Vehicle-fed } \\ \%\end{array} & \begin{array}{c}\text { MBP-fed } \\ \%\end{array} \\ \text { TUNEL }^{+} / \mathrm{Tg}^{\mathrm{A}} & 5.1 & 58.5 \\ \mathrm{Fas}^{+} / \mathrm{CD}^{\mathrm{B}} & 9.2 & 16.7\end{array}$

AFITC-TUNEL-positive cells within the $\mathrm{PE}-\mathrm{V} \beta 8^{+} / \mathrm{Cyc}-\mathrm{CD} 4^{+}$population 7 days after MBP or vehicle feeding. ${ }^{B} \mathrm{PE}-$-Fas-positive cells within the $\mathrm{Cyc}-\mathrm{CD} 4^{+}$population 10 days after MBP or vehicle feeding. in TUNEL ${ }^{+} \mathrm{Tg}$ cells (Table 1 ). In addition, MBP feeding resulted in enhanced Fas expression on $\mathrm{CD}^{+}$cells (Table 1) and a fourfold increase in FasL expression on MHC class II-positive cells (data not shown). Therefore, these observations indicate that in addition to inducing anergy, high-dose oral antigen administration can result in apoptosis of antigen-specific $T$ cells.

\section{Discussion}

Studies presented here explore the fate of MBP-specific $T$ cells in vivo after high-dose MBP feeding by following the population over time in thymectomized $\mathrm{Tg}$ mice. To avoid the confounding influence of newly released $T$ cells, we utilized thymectomized animals instead of $\mathrm{Rag}^{-1-}$ mice due to the high level of spontaneous EAE that is observed when the Rag mutation is introduced onto the MBP TCR Tg background (14). A single high dose of MBP led to diminished function and deletion of MBP-specific Tg T cells. Preceding deletion, there is an early in vivo antigen-recognition event characterized by TCR downmodulation, CD69 upregulation, and heightened Th1 and Th2 cytokine responses that correlates with protection from EAE. Analysis of Th1-type (IL-2, IFN- $\gamma$ ), Th2-type (IL-4, IL-5), and TGF- $\beta$ cytokines failed to demonstrate evidence for active suppression or immune deviation. Instead, we observed that the $\mathrm{V} \beta 8^{+} / \mathrm{CD}^{+}$phenotype and functional responses ultimately declined within 14 days of feeding. TUNEL analysis then confirmed apoptosis of MBP-specific cells after a single high-dose MBP feeding. Interestingly, we also observed a brief period characteristic of anergy, when $\mathrm{VB} 8^{+} / \mathrm{CD}^{+}$cells were demonstrable, but showed decreased IL-2 production and proliferation responses in vitro.

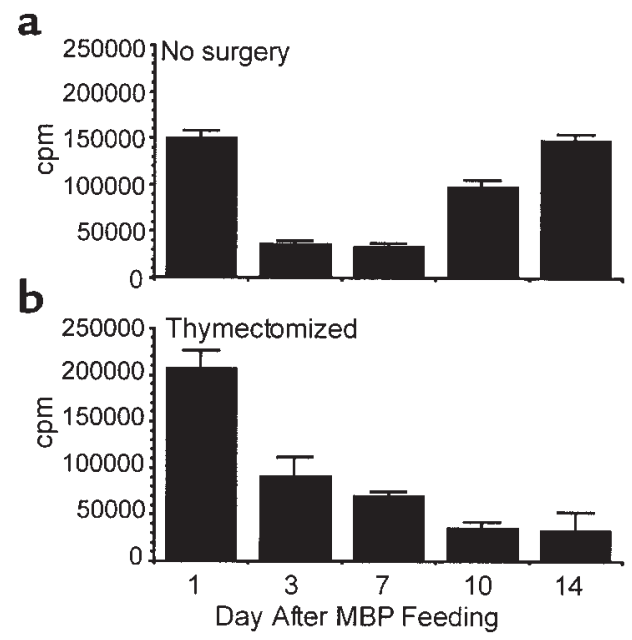

\section{Figure 6}

$\mathrm{V} \beta 8^{+} / \mathrm{CD} 4^{+} \mathrm{Tg} \mathrm{T}$-cell function declines after MBP feeding. Euthymic and thymectomized MBP TCR Tg mice were fed $100 \mathrm{mg} \mathrm{MBP}$ and sacrificed $1,3,7,10$, and 14 days after feeding. $L N$ cell proliferative responses to NAc1-11 were measured by in vitro $\left[{ }^{3} \mathrm{H}\right]$ thymidine uptake. Data are representative of six separate experiments. (a) Each bar is the mean cpm of triplicate wells \pm SEM. (b) Each bar is the mean cpm of cultures from two mice per group \pm SEM. 
T-cell activation has also been shown to precede oral tolerance in nondisease model systems. Cytochrome (cyt) c TCR Tg mice fed repeated low doses of cyt c exhibited a reduction in $\mathrm{Tg} \mathrm{TCR}^{+}$cells and upregulation of CD69 in splenocyte populations (24). Similarly, when OVA-specific $\mathrm{Tg} \mathrm{TCR}^{+} \mathrm{T}$ cells were adoptively transferred to $\mathrm{BALB} / \mathrm{c}$ recipients, a single oral dose of OVA resulted in activation and proliferation of OVAspecific $T$ cells leading to T-cell anergy (25). In other studies, repeated oral administration of OVA resulted in reduced Tg TCR ${ }^{+}$cells in SPL and LNs of BALB/c recipients concomitant with increased IFN- $\gamma$, IL-4, and TGF- $\beta$ production upon in vitro re-stimulation with OVA (26). The level of TCR downmodulation in vivo has been shown to be directly related to the dose of tolerogen (27). However, to our knowledge, ours is the first demonstration of this in mucosal tolerance.

Two independent mechanisms of TCR downmodulation have been described previously (28). PMA-induced T-cell stimulation is believed to activate protein kinase $\mathrm{C}$ (PKC) and result in TCR internalization and then reexpression when the stimulus is removed (29). TCR downmodulation after specific ligand interaction is thought to be PKC independent and results in lysosomal degradation of the TCR (30). It is not known whether these pathways of TCR downmodulation are interrelated. In work presented here, MBP-fed animals with decreased surface TCR demonstrated increased intracellular expression of $\mathrm{V} \beta 8$ protein, resulting either from cytoplasmic localization of extracellular TCR or newly synthesized TCR. It is unlikely that the return of $\mathrm{V} \beta 8^{+} / \mathrm{CD}^{+}$cells represents $\mathrm{Tg}$ cell progeny, as we did not observe evidence for in vivo proliferation of MBP-specific cells. Rather, the restoration of $\mathrm{V} \beta 8^{+} / \mathrm{CD} 4^{+}$cells likely results from re-expression of the Tg TCR facilitated by factors provided in lymphoid tissue microenvironments.

Despite the profound reduction in TCR expression, a $\mathrm{V} \beta 8^{+} / \mathrm{CD}^{+} \mathrm{Tg}$ population with an activated phenotype $\left(\mathrm{CD}^{2} 9^{+}\right)$is present 1 day after antigen feeding in all lymphoid organs examined. This indicates that responses to high doses of fed antigen are not limited to the gut-associated lymphoid tissue. Indeed, in cyt c TCR Tg mice, splenocytes isolated 6 hours after cyt c feeding were able to stimulate naive $\mathrm{Tg} \mathrm{T}$ cells when cocultured in vitro (24). These authors concluded that orally administered cyt $\mathrm{c}$ was widely disseminated and was present in the SPL after feeding. Interestingly, a single low dose of cyt c $(0.5 \mathrm{mg})$ induced increases in CD69 expression similar to results presented here. Thus, both high and low doses of orally administered antigen induce peripheral T-cell activation. Heightened in vitro cytokine responses to MBP most likely resulted from $\mathrm{VB} 8^{+} / \mathrm{CD}^{+} / \mathrm{CD} 69^{\text {hi }} / \mathrm{CD} 62 \mathrm{~L}^{\text {lo }} \mathrm{T}$ cells, as TCR expression is required to ligate antigen. Given the high frequency of MBP-specific T cells in MBP TCR Tg mice, it is possible that this population did not encounter sufficient antigen in vivo to downmodulate TCR expression completely but did receive enough TCR ligation to signal changes in antigen responsiveness.

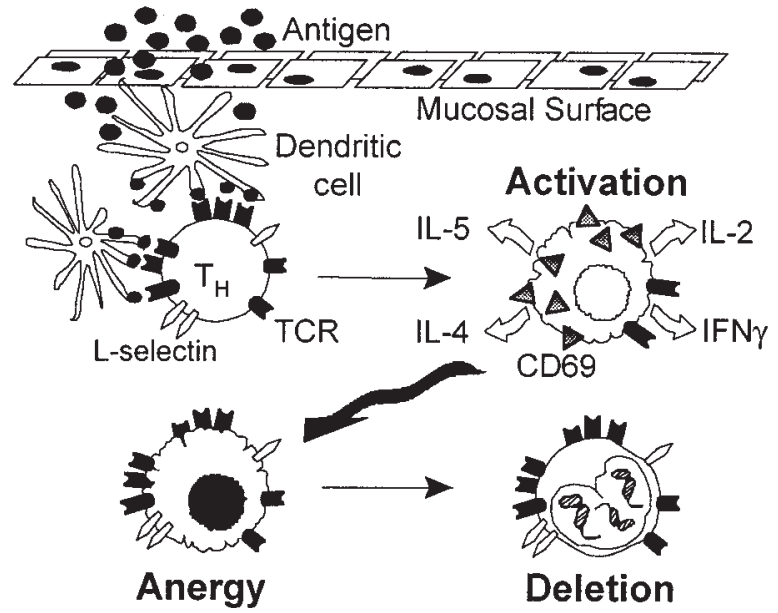

Figure 7

Proposed model for tolerance induction after a high dose of orally administered antigen.

The ultimate fate of $\mathrm{T}$ cells, whether activated or hyporesponsive, is most likely determined by the antigen presenting cell (APC). Dendritic cells (DCs) as APCs have been shown to initiate active immunity and/or induce T-cell tolerance, depending on their maturation state. DC maturation can be triggered by CD40 ligand, inflammatory cytokines, the presence of necrotic cells, or viral and bacterial constituents (31, 32). Unlike immature DCs, mature DCs are potently immunogenic (31). We observed a short-lived period of protection after feeding MBP to Tg mice (Figure 3). Perhaps the bacterial products present during MBP/CFA immunization induce DC maturation and promote immunogenicity to MBP that overrides mucosally induced tolerance (Figure 2). The excessive number of MBP-specific T cells in MBP TCR Tg mice is noteworthy and can explain the fact that protection from EAE is less dramatic and more short-lived than observed in orally tolerized conventional rats and mice $(1,3)$. Because Liu et al. have recently demonstrated that DCs in the intestinal wall can acquire soluble protein antigen and migrate into peripheral lymph to prime antigen-specific T cells (33), we are currently investigating the role of DCs in the induction of oral tolerance.

By integrating the data presented here with work by others, we propose a model for oral tolerance induction (Figure 7). Antigen traverses the gut epithelium and is presented by APCs, presumably DCs. Antigen-specific $\mathrm{CD} 62 \mathrm{~L}^{+} / \mathrm{CD}^{+} \mathrm{T}$ cells encounter a high dose of antigen presented on DCs, which triggers TCR downmodulation, CD62L downregulation, and CD69 upregulation within 24 hours. In vitro, these cells are hyper-responsive to antigen, as measured by IL- 2 , IFN- $\gamma$, IL- 4 , and IL5 production. After 3 days, CD62L and TCR expression return, whereas CD69 expression and responses to antigen diminish, i.e., $\mathrm{T}$ cells are anergic. Finally $(7-14$ days after feeding), fewer antigen-specific $T$ cells are detectable, in vitro responses decline, and apoptosis of 
Tg cells is seen. Collectively, these observations suggest that the mechanism of oral tolerance after high doses of antigen follows an in vivo continuum of activation, anergy, and then deletion.

\section{Acknowledgments}

The authors thank Phillip Popovich, Fei Song, Kennichi Dowdell, Karen Cox, Richard Wardrop, Carey Etling, and Dick Trezza for their assistance with these studies, and Charles Janeway for supplying the nucleus for our MBP TCR Tg breeding colony. This work was supported by NIH grant AI 35960, AI 43376, National Multiple Sclerosis Society grant RG 2302, and the Bremer Foundation.

1. Bitar, D.M., and Whitacre, C.C. 1988. Suppression of EAE by the oral administration of MBP. Cell. Immunol. 112:364-370.

2. Higgins, P.J., and Weiner, H.L. 1988. Suppression of EAE by oral administration of MBP and its fragments. J. Immunol. 140:440-445.

3. Meyer, A.L., Benson, J.M., Gienapp, I.E., Cox, K.L., and Whitacre, C.C. 1996. Suppression of murine chronic REAE by the oral administration of MBP. J. Immunol. 157:4230-4238.

4. Benson, J.M., et al. 1999. Oral administration of MBP is superior to myelin in suppressing established REAE. J. Immunol. 162:6247-6254.

5. Miller, A., Lider, O., Roberts, A.B., Sporn, M.B., and Weiner, H.L. 1992. Suppressor T cells generated by oral tolerization to MBP suppress both in vitro and in vivo immune responses by the release of TGF $\beta$ after antigen-specific triggering. Proc. Natl. Acad. Sci. USA. 89:421-425.

6. Chen, Y., Kuchroo, V.K., Inobe, J., Hafler, D.A., and Weiner, H.L. 1994. Regulatory T cell clones induced by oral tolerance: suppression of EAE. Science. 265:1237-1240.

7. Fishman-Lobell, J., Friedman, A., and Weiner, H.L. 1994. Different kinetic patterns of cytokine gene expression in vivo in orally tolerant mice. Eur. J. Immunol. 24:2720-2724.

8. Hurst, S.D., Sitterding, S.M., Ji, S., and Barrett, T.A. 1997. Functional differentiation of T cells in the intestine of TCR transgenic mice. Proc. Natl. Acad. Sci. USA. 94:3920-3925.

9. Whitacre, C.C., Gienapp, I.E., Orosz, C.G., and Bitar, D.M. 1991. Oral tolerance in EAE. III. Evidence for clonal anergy. J. Immunol. 147:2155-2163.

10. Van Houten, N., and Blake, S.F. 1996. Direct measurement of anergy of antigen-specific $\mathrm{T}$ cells following oral tolerance induction. $J$. Immunol. 157:1337-1341.

11. Pape, K.A., Merica, R., Mondino, A., Khoruts, A., and Jenkins, M.K. 1998. Direct evidence that functionally impaired CD4+ T cells persist in vivo following induction of peripheral tolerance. J. Immunol. 160:4719-4729.

12. Chen, Y., et al. 1995. Peripheral deletion of antigen-reactive T cells in oral tolerance. Nature. 376:177-180.

13. Marth, T., Strober, W., and Kelsall, B.L. 1996. High dose oral tolerance in OVA TCR-Tg mice: systemic neutralization of IL-12 augments
TGF- $\beta$ secretion and T cell apoptosis. J. Immunol. 157:2348-2357. 14. Lafaille, J.J., Nagashima, K., Katsuki, M., and Tonegawa, S. 1994. High incidence of spontaneous EAE in immunodeficient anti-MBP TCR Tg mice. Cell. 78:399-408.

15. Deibler, G.E., Martenson, R.E., and Kies, M.W. 1972. Large scale preparation of MBP from central nervous tissue of several mammalian species. Prep. Biochem. 2:139-165.

16. Swanborg, R.H., Swierkosz, J.E., and Saieg, R.G. 1974. Studies on the species-variability of EAE in guinea pigs and rats. J. Immunol. 112:594-600.

17. DeMatteo, R.P., Markmann, J.F., and Raper, S.E. 1995. An improved technique of thymectomy in the adult mouse. Transplantation. 59:787-789.

18. Forsthuber, T., Yip, H.C., and Lehmann, P.V. 1996. Induction of TH1 and TH2 immunity in neonatal mice. Science. 271:1728-1730.

19. Chen, Y.H., and Weiner, H.L. 1996. Dose-dependent activation and deletion of antigen-specific T cells following oral tolerance. Ann. NY Acad. Sci. 778:111-121.

20. Viola, A., and Lanzavecchia, A. 1996. T cell activation determined by TCR number and tunable thresholds. Science. 273:104-106.

21. Carter, L.L., and Swain, S.L. 1998. From naive to memory. Development and regulation of CD4+ T cell responses. Immunol. Res. 18:1-13.

22. Testi, R., D'Ambrosio, D., De Maria, R., and Santoni, A. 1994. The CD69 receptor: a multipurpose cell-surface trigger for hematopoietic cells. Immunol. Today. 15:479-483.

23. Jenkins, M.K., Pardoll, D.M., Mizuguchi, J., Chused, T.M., and Schwartz, R.H. 1987. Molecular events in the induction of a nonresponsive state in IL-2-producing helper T-lymphocyte clones. Proc. Natl. Acad. Sci. USA. 84:5409-5413.

24. Gutgemann, I., Fahrer, A.M., Altman, J.D., Davis, M.M., and Chien, Y.H. 1998. Induction of rapid $\mathrm{T}$ cell activation and tolerance by systemic presentation of an orally administered antigen. Immunity. 8:667-673

25. Sun, J., Dirden-Kramer, B., Ito, K., Ernst, P.B., and Van Houten, N. 1999. Antigen-specific T cell activation and proliferation during oral tolerance induction. J. Immunol. 162:5868-5875.

26. Chen, Y., Inobe, J., and Weiner, H.L. 1997. Inductive events in oral tolerance in the TCR Tg adoptive transfer model. Cell. Immunol. 178:62-68.

27. Ferber, I., et al. 1994. Levels of peripheral T cell tolerance induced by different doses of tolerogen. Science. 263:674-676.

28. Lauritsen, J.P., et al. 1998. Two distinct pathways exist for down-regulation of the TCR. J. Immunol. 161:260-267.

29. Salio, M., Valitutti, S., and Lanzavecchia, A. 1997. Agonist-induced TCR down-regulation: molecular requirements and dissociation from T cell activation. Eur. J. Immunol. 27:1769-1773.

30. Valitutti, S., Muller, S., Salio, M., and Lanzavecchia, A. 1997. Degradation of TCR-CD3- $\zeta$ complexes after antigenic stimulation. J. Exp. Med. 185:1859-1864.

31. Steinman, R.M., Turley, S., Mellman, I., and Inaba, K. 2000. The induction of tolerance by DCs that have captured apoptotic cells. J. Exp. Med. 191:411-416.

32. Sauter, B., et al. 2000. Consequences of cell death: exposure to necrotic tumor cells, but not primary tissue cells or apoptotic cells, induces the maturation of immunostimulatory DCs. J. Exp. Med. 191:423-433.

33. Liu, L.M., and MacPherson, G.G. 1993. Antigen acquisition by DCs: intestinal DCs acquire antigen administered orally and can prime naïve T cells in vivo. J. Exp. Med. 177:1299-1307. 